\title{
CARACTERIZAÇÃO DE UNIDADES AGRÍCOLAS FAMILIARES PRODUTORAS DE LEITE NO NORTE DO ESTADO DE MINAS GERAIS
}

\author{
Characterization of family dairy farm in the \\ north of Minas Gerais state, Brazil
}

\begin{abstract}
Isabela Rocha Menezes ${ }^{I}$, Anna Christina de Almeida ${ }^{*}$, Maximiliano Soares Pinto ${ }^{I}$,

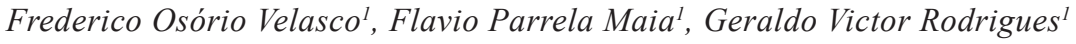

\begin{abstract}
RESUMO
A produção de leite na mesorregião do Norte de Minas é a mais baixa do estado. No entanto notou-se um crescimento considerável nos últimos anos, com a necessidade de diagnósticos socioeconômicos e técnicos geradores de informações norteadoras para a adoção de medidas estratégicas para impulsionar a produção. Portanto, o objetivo desse trabalho foi diagnosticar a produção leiteira em 30 Unidades Agrícolas Familiares Produtoras de Leite, nos municípios de Juramento (15) e Montes Claros (15), Norte de Minas Gerais, por meio do estudo de caso, utilizandose questionários semiestruturados que continham informações sobre manejo geral e sanitário, características socioeconômicas e levantamento da utilização de práticas agroecológicas na produção de leite. Para aplicação dos questionários empregou-se a abordagem sistêmica. Das 30 propriedades, $86 \%$ possuíam a atividade leiteira como exploração principal, seguida de $14 \%$ de exploração mista. Apresentavam baixas a médias condições tecnológicas, e a maior parte dos agricultores possuía outra fonte de renda além da produção de leite. Observou-se em 100\% das propriedades a ausência de práticas agroecológicas no processo produtivo. A produção de leite na agricultura familiar é bastante disseminada, em propriedades com deficiências de manejo geral e sanitário, constituídas por famílias de baixa a média renda e dependentes da produção de leite para complementar sua renda.

Palavras-chave: agricultura familiar; produção leiteira; diagnóstico socioeconômico.
\end{abstract}

1 Universidade Federal de Minas Gerais (UFMG), Instituto de Ciências Agrárias, Av. Universitária, 1000, Universitário, 39404-006, Montes Claros, MG, Brasil. E-mail: annachristinadealmeida@gmail.com

* Autor para correspondência.

Recebido / Received: 13/11/2013

Aprovado / Approved: 14/04/2014 


\begin{abstract}
Milk production in the middle region of northern Minas Gerais state is the lowest in the state. However we noticed a considerable growth in recent years. It is important to conduct socioeconomic and generators technicians guiding information for the adoption of policy measures to boost production diagnostics. The aim of this study was to diagnose the production of milk in 30 family dairy farms in Juramento (15) and Montes Claros (15) city, Northern Minas Gerais; by a case study, semi-structured questionnaires that included information about general and sanitary handling, socio-economic characteristics and also surveyed the use of agro-ecological practices in milk production. A systemic approach was used in the application of questionnaires. Out of the 30 properties, $86 \%$ have the dairy activity as the main one, followed by $14 \%$ of mixed activities. They have low to average technology and most farmers have another source of income in addition to milk production. The absence of agro-ecological practices in the production process was observed in $100 \%$ of the properties. It was concluded that milk production in family farms is very widespread, and the main characteristics are of properties with general and sanitary handling problems; the socio-economic characteristics are of families with low to average income and dependent on the milk production to complement it. Regarding the agro-ecological practices, it can be concluded that they were rarely used in the properties surveyed.
\end{abstract}

Keywords: family farming; milk production, rural diagnosis.

\section{INTRODUÇÃO}

A atividade leiteira se insere em uma cadeia produtiva de alta complexidade, que exige especialização dos produtores para atender as exigências e as demandas do mercado mundial (ARAUJO; SILVA, 2014). Nos últimos anos, ela sofreu consideráveis modificações estruturais, aumentando a necessidade do conhecimento e caracterização das atividades dentro dos diferentes e em regionais sistemas de produção (MONTEIRO et al. 2007). Devido a isso, o conhecimento da cadeia produtiva de leite torna-se importante, pois permite traçar o perfil da produção de uma determinada bacia leiteira e com isso pontuar possíveis gargalos existentes na produção (MARCON et al. 2014).

O diagnóstico de cada ambiente de produção permite gerar informações importantes para a tomada de decisões rápidas e objetivas, tanto para os produtores quanto para os órgãos governamentais e de pesquisas. Dessa maneira torna a atividade mais eficiente e competitiva (LOPES et al., 2004) além de corresponder às demandas do mercado.

Foram produzidos no ano de 2012, 470 bilhões de litros de leite em todo o mundo. Desses, um total de 32 bilhões foram produzidos no Brasil, o qual se inseriu em quinto lugar no ranking mundial de países com maior produção leiteira (USDA, 2013). Nos últimos cinco anos a produção nacional cresceu, entretanto, algumas regiões com menor aptidão e tradição para este tipo de produção, apresentaram desempenhos insatisfatórios. Tem-se como exemplo a região norte do estado de Minas Gerais que apresentou os piores desempenhos produtivos nesta atividade, e consequentemente os piores rendimentos financeiros negativos. Com isso, foi considerada a região de menor tradição leiteira no referido estado (SEBRAE-MG; FAEMG, 2006), o qual é 
um dos maiores produtores do país. Mas, apesar da baixa contribuição da região na produção de leite, houve entre os anos de 2006 e 2010 um incremento de 59,4\% nessa produção, totalizando em 2010, 439.812 mil litros produzidos. No mesmo período, sua participação na produção estadual cresceu de $3,78 \%$ para $5,24 \%$ (IBGE, 2011).

Em 2009, no Brasil, foram ordenhadas 384.959, a produção de leite da mesorregião do norte de Minas Gerais somou 311.754 mil litros, o que representa 3,93\% da produção do Estado para o mesmo período, de 7.931.115 mil litros. No período de 1995-2008, o produto lácteo nacional registrou aumento de $74,7 \%$ no volume de leite produzido (mil litros) e de $407,5 \%$ no valor da produção (IBGE/SIDRA, 2010).

Os países de maiores produção geralmente possuem um alto nível tecnológico, com animais especializados para essa atividade e um manejo alimentar, sanitário e reprodutivo intenso. Já em países e regiões menos especializadas é comum encontrar desde produtores altamente especializados até produtores com o mínimo possível de tecnologia e informações sobre práticas adequadas de manejo (TKAEZ et al., 2004).

No Brasil, de modo geral, o leite é obtido sob condições precárias de higiene e sanidade, apresentando elevado número de microrganismos, e um risco ao consumidor (CERQUEIRA et al., 1995). Estudos na produção de leite familiar no Noroeste do Estado de Minas Gerais demonstraram que práticas comuns essenciais para garantir a sanidade do rebanho e, consequentemente, a qualidade do leite, são pouco adotadas, como vacinação do rebanho e prevenção da mastite (ALTAFIN et al., 2009). Existindo, portanto, poucos estudos sobre a produção de leite da agricultura familiar.

Diante das transformações espaciais, sociais e econômicas ocorridas ao longo dos anos e ao longo de cada região produtora de leite, e da importância de se realizar o diagnóstico dos ambientes de produção leiteira, é imprescindível conhecer o perfil de produtores de base familiar que atuam na atividade leiteira predominantes na região norte do estado de Minas Gerais e quais os manejos utilizados nessas unidades de produção. Justificando assim o objetivo de caracterizar 30 unidades agrícolas familiares produtoras de leite localizadas nos municípios de Juramento e Montes Claros, norte de Minas Gerais, observando o perfil do produtor, caracterização das propriedades e do manejo com os animais, assim como levantar informações sobre a utilização de práticas agroecológicas nessas propriedades.

\section{MATERIAL E MÉTODOS}

Para o desenvolvimento desse trabalho, inicialmente identificou-se 30 unidades agrícolas familiares produtoras de leite dos municípios de Juramento e Montes Claros, norte de Minas Gerais. Foram escolhidas propriedades integrantes do "Programa de Apoio a Agricultores Familiares do norte de Minas Gerais em Produção, Higiene e Saúde Pública", o qual atua há mais de cinco anos com atividades relacionadas à promoção da melhoria da qualidade dos produtos de origem animal, obtidos na agricultura familiar, bem como na melhoria da saúde pública na região Norte de Minas Gerais.

Consideraram-se propriedades familiares as que possuíam área agrícola inferior a quatro módulos fiscais, origem da mão de obra prioritariamente familiar e renda oriunda principalmente da atividade agrícola, de acordo com a Lei 11.326 (BRASIL, 2006). Em todas as propriedades escolhidas seus proprietários foram entrevistados por meio de questionários semiestruturados. Esses continham informações sobre o perfil socioeconômico dos produtores, questões sobre o manejo geral e manejo sanitário e práticas 
agroecológicas realizadas nas propriedades. Essas entrevistas foram realizadas por estudantes do curso de Zootecnia do Instituto de Ciências Agrárias da Universidade Federal de Minas Gerais (ICA/UFMG), que foram capacitados para essa atividade, a fim de se obter maior confiabilidade nos dados fornecidos pelos produtores, sob supervisão e orientação dos responsáveis pela pesquisa. Após a obtenção dos dados, esses foram compilados por meio do software Excel ${ }^{\circledR}$, realizando-se uma analise estatística descritiva, para caracterizar os sistemas de produção nas propriedades entrevistadas.

\section{RESULTADOS E DISCUSSÃO}

Nas 30 propriedades estudadas, $86 \%$ possuíam a atividade leiteira como exploração principal, seguida de $14 \%$ de exploração mista de leite, corte, avicultura, entre outras. Segundo Souza (2008), a produção de leite é significativamente disseminada na agricultura familiar por não existirem barreiras à entrada. Em geral, a família já produz leite para o consumo interno, e destina o restante para a comercialização ou processamento. Buainaim et al. (2003) afirmaram que esse tipo de agricultura é profundamente heterogênea, em termos de disponibilidade de recursos, acesso ao mercado, capacidade de geração de renda e acumulação. Justifica-se pelo fato de a maior parte das propriedades estudadas possuir a atividade de leite como exploração principal, e ainda a presença dessa atividade associada a outros tipos de exploração agropecuária.

Nos rebanhos leiteiros, 26\% eram mestiços de origem desconhecida, $74 \%$ mestiços de origem conhecida e nenhum animal puro de origem (PO). Entre as principais composições genéticas envolvidas no rebanho, 93\% das propriedades possuíam animais com características da raça holandesa, 90\% gir leiteiro, $70 \%$ nelore e $10 \%$ outras raças menos conhecidas e exploradas no país.
A escolha da raça assume papel importante na busca por melhoria na produção de leite, uma vez que, existe raças que são mais especializadas para esta atividade e a sua utilização irá proporcionar maiores índices de produção (BARRETO, 2007). Segundo Cerdótes et al. (2004), a produção e a qualidade do leite da vaca são influenciadas por fatores ambientais, no qual se destacam principalmente a alimentação e fatores genético. A escolha de raças adaptadas ao local de produção é importante, pois sofrem menor interferência do ambiente. Observouse nas propriedades estudadas que a maior parte possui um rebanho muito heterogêneo e que apesar de serem propriedades leiteiras, os animais não eram tão especializados para devido fim, o que pode constituir um fator para a ineficiência da produção.

De acordo com Carvalho Junior (2011), baixa tecnificação e fatores ambientais relevantes para a pecuária leiteira, custos de produção elevados e baixa remuneração dada ao leite talvez justifiquem as misturas raciais encontradas na região. Em 100\% das propriedades o rebanho era composto por animais caracterizados por possuir variadas composições genéticas. Ainda conforme o autor, animais mestiços produzidos com participação de animais zebuínos, apesar de menos especializados, apresentam maior rusticidade e demandam menor refinamento tecnológico. Consequentemente, possibilita custos de produção mais acessíveis, o que justificaria o fato de $74 \%$ das propriedades aqui estudadas possuírem animais mestiços em seus rebanhos.

Em 64\% das unidades produtivas de leite, o número total de animais encontrados nos rebanhos foi de até 50 animais por unidade de produção; em $13 \%$, de 51 a 100 animais por unidade de produção, e em $23 \%$, encontraram-se acima de 100 animais por unidade de produção. De acordo com Alende (2006), propriedades cuja fonte de renda 
principal é a produção de leite, possuem, em média, um rebanho com 20 a 30 animais. Isso pode ser confirmado no presente estudo, uma vez que na maioria das unidades estudadas encontraram-se no máximo rebanhos com 50 animais por unidade de produção e em $87 \%$ destas propriedades, a atividade leiteira foi considerada como a principal fonte de renda da unidade de produção. Ainda segundo o autor, esse tipo de unidade produtiva ocupa estratos de intervalo de área entre 20 e 30 hectares. Novamente, isso foi comprovado na presente pesquisa, no qual encontrou-se em 34\% das unidades uma área total de 1 a 10 hectares; em 34\%, áreas entre 11 a 50 hectares e em $16 \%$ destas com áreas de 51 a 100 hectares e em 16\% acima de 100 hectares.

Em $66 \%$ das propriedades as médias de produção diária de leite variaram entre 50 até 250 litros de leite. Em 34\% eram produzidos 50 litros de leite diários. Barros et al. (2001) estipularam as quantidades de 53 litros, entre 53 a 133 litros, acima de 133 litros de leite diários, para caracterizar, respectivamente, pequenos, médios e grandes produtores de leite. A maior parte das propriedades aqui estudadas enquadra-se como de média produção. Segundo esses autores, pequenos e médios produtores possuem rebanhos de animais mestiços, e os pequenos empregam a ordenha manual, o que é compatível com os dados encontrados no presente trabalho, pois apenas 3,33\% utilizavam a ordenha mecânica. Contrariamente, grandes e médios produtores possuem geralmente rebanhos de raças especializadas para produção de leite e utilizam ordenha mecânica (BARROS et al., 2001).

O principal meio de exploração encontrado em $63,33 \%$ das propriedades foi o extensivo, seguido do sistema semiconfinado, em 36,7\%. A classificação da exploração como intensivo e extensivo define claramente o manejo alimentar e produtivo adotado, e a importância maior dos fatores de produção em função do sistema adotado. Criações extensivas mantêm os animais soltos em campo nativo, com pouca preocupação em relação aos diferentes fatores de produção. Em sentido oposto, o manejo intensivo procura a maior eficiência possível em cada fator de produção (KRUG, 2001), necessita de maiores investimentos em estruturas físicas, tecnologias e rebanhos mais especializados e no manejo em geral das unidades produtivas. Como a maior parte das propriedades estudadas caracterizou-se entre pequeno (34\%) e médio porte $(66 \%)$ de produção, ficou evidente menores investimentos em estrutura física para criar os animais semi-intensivamente se comparados às explorações intensivas. Para se verificar as características das instalações nas quais os animais eram manejados e ordenhados, três níveis de qualidade foram definidos para classificação: ruins, quando o local de ordenha encontrava-se com piso de terra, postes ou mourões em péssimo estado de conservação; sem instalações apropriadas de ordenha e salas de esperas, e sem cobertura para proteger do sol e chuvas; satisfatórias, quando o local apresentava-se com piso cimentado; os postes ou mourões estavam em bom estado de conservação, local coberto e a sala de ordenha era separada da sala de espera e do bezerreiro; e excelentes se a sala de ordenha possuía piso apropriado e com declive adequado para escoamento de água, com sala adequada de armazenamento do leite, espera e bezerreiro, e possuía fácil acesso a fonte de água e alimentação para os animais. Em 66,7\% das propriedades estudadas, as instalações apresentaram condições ruins; $30 \%$ condições satisfatórias, e apenas 3,3\% excelente estado. De acordo com Alende (2006), sistemas de produção cuja fonte de renda principal é a atividade leiteira possuem infraestrutura composta por um galpão com estábulo para ordenha, nem sempre de alvenaria, nas paredes e pisos, e tronco para contenção dos animais. Em 66,7\% das propriedades, os animais são originados do 
próprio rebanho, 33,3\% adquiridos de outros criadores. Destes, 93,3\% das propriedades não exigiam atestado de vacinação e exames negativos de doenças como brucelose, para a compra dos animais, e apenas $6,7 \%$ exigem esses documentos.

O estudo de programas de saúde animal para a prevenção de enfermidades em sistemas de produção leiteiras em condições zootécnicas e climáticas do país deve ser estimulado (DEL FAVA et al., 2003), para se evitar a ocorrência de doenças e consequentemente as perdas ocasionadas por estas. É importante respeitar as exigências de vacinação preconizadas pelo Ministério da Agricultura, Pecuária e Abastecimento (MAPA) (BRASIL, 2009) e as necessidades de cada propriedade. A Tabela 1 apresenta as práticas de vacinações adotadas no rebanho nas propriedades em estudo.

Apenas as vacinas exigidas pelo MAPA possuíam alta frequência de adoção nas propriedades que as implementavam, como para a febre aftosa, raiva bovina (exigidas apenas para áreas endêmicas e de risco de ocorrência) e brucelose. Somente para a primeira doença encontrou-se a adoção de $100 \%$ das propriedades que a realizavam. Essa ocorrência de vacinação contra a febre aftosa deve-se provavelmente pela obrigatoriedade da vacinação pelo MAPA, e por ser muito fiscalizada por meio das notas fiscais emitidas aos produtores na compra das vacinas.

Em $100 \%$ das propriedades, era realizada a vermifugação, porém em $60 \%$ das propriedades ela acontecia semestralmente, $13,3 \%$ trimestralmente, em 3,4\% quinzenalmente, e $23,3 \%$ dos produtores não souberam responder sobre o intervalo em que seus rebanhos eram vermifugados. As diversas técnicas de controle das parasitoses dos rebanhos bovinos são desconhecidas pela maioria dos pecuaristas, os quais não percebem ainda os prejuízos provocados pelas endoparasitoses. As estratégias de controle de helmintos em bovinos dependem de processo de educação sanitária continuada dos agentes envolvidos para se estabelecer conhecimento coletivo (DELGADO et al., 2009).

Em 73,3\% das propriedades havia o controle de carrapatos e ectoparasitoses. Quanto à frequência do controle de carrapatos, verificou-se que em $60,60 \%$ ele ocorria semestralmente, $13,14 \%$ trimestralmente, em 23,3\% quinzenalmente, e em nenhuma propriedade havia o controle mensal. Vieira (2005) afirmou que a sanidade do rebanho, aliado às práticas de manejo e à nutrição, é essencial para o aumento da produção e

Tabela 1 - Práticas de vacinações adotadas em rebanhos leiteiros em 30 unidades agrícolas familiares produtoras de leite nos municípios de Juramento e Montes Claros, norte de Minas Gerais

\begin{tabular}{lcc}
\hline \multicolumn{1}{c}{ Doenças } & Adoção de prática (\%) & N* \\
\hline Brucelose & 56,6 & 17 \\
Campilobacteriose & 10 & 3 \\
Clostridioses & 70 & 21 \\
Febre aftosa & 100 & 30 \\
Rinotraqueíte bovina Infecciosa & 0 & 0 \\
Diarreia viral bovina & 6,7 & 2 \\
Leptospirose & 10 & 3 \\
Paratifo & 10 & 3 \\
Raiva bovina & 96,6 & 29 \\
\hline
\end{tabular}

*número de unidades familiares produtoras de leite. 
produtividade da propriedade, por isso, o produtor deve adaptar o seu manejo de acordo com sua realidade.

No presente estudo, 53,33\% dos agricultores familiares responderam sobre as principais doenças ocorridas em seus rebanhos, como a mastite, seguida de verminoses $(33,3 \%)$; problemas reprodutivos $(23,33 \%)$ e pododermatite $(16,66 \%)$. De acordo com Vieira (2005), quando existe manejo sanitário deficiente ocorre maiores probabilidades de se encontrarem animais doentes, queda da produção e produtividade, maiores gastos com medicamentos, e, consequentemente, prejuízos econômicos e diminuição da lucratividade.

Em 33,3\% das propriedades não havia controle reprodutivo do rebanho, e $66,6 \%$ faziam algum controle, como monta natural controlada ou inseminação artificial. Em 90\% das propriedades a reprodução era por meio de monta natural, e $10 \%$ utilizavam a inseminação artificial. Em 50\% das propriedades os touros eram próprios, e em $50 \%$ os mesmos eram emprestados e/ou havia compra de doses de sêmens. Em todas as propriedades (100\%) não se utilizava o rufião para identificação do cio das vacas, e não se fazia o diagnóstico da gestação por meio da técnica de apalpação. De acordo com Leite et al. (2001), a eficiência reprodutiva do rebanho é um dos componentes mais importantes na performance econômica na propriedade de produção de leite, sendo que falhas de manejo e registro de dados comprometedoras da eficiência reprodutiva do rebanho, interferem nos índices produtivos.

Ao se verificar as características socioeconômicas das propriedades em estudo, observou-se que eram ocupadas aproximadamente por um (1) membro homem (46,66\% das propriedades), e uma (1) mulher (59,99\%). Em estudos de Silva (2010) em uma comunidade no norte de Minas Gerais, que possui agricultores familiares produtores de leite, constatou-se que $66,7 \%$ dos membros eram do sexo masculino e 33,3\% do sexo feminino. Entretanto, a causa da maior incidência de homens na comunidade não foi identificada.

Conforme a classificação de Schneider (2003), a composição da família de agricultores se caracterizava pela maior presença de idosos e de crianças, e normalmente os netos permaneciam algum tempo morando na propriedade com os avós. Também essa composição foi confirmada pela pesquisa em estudo: 38\% dos homens presentes nessas propriedades possuíam, em média, 19 a 65 anos de idade, assim como $37 \%$ das mulheres.

Das 15 propriedades rurais de Montes Claros, 13 (87\%) possuíam outra atividade remunerada, com ou sem vínculo empregatício. No município de Juramento 10 propriedades tinham outra atividade remunerada, com e/ou sem vínculos empregatícios, aposentadorias e outros benefícios, na composição da renda familiar do produtor. Silva (2010) estudou uma comunidade no norte de Minas Gerais e observou que os agricultores familiares possuíam como fonte de renda as tranferências públicas, além da produção de leite e lavoura. A atividade de produção de leite, embora tenha permitido, no decorrer dos anos, a sobrevivência e permanência de muitas famílias no meio rural, vivenciou momentos de estagnação e descapitalização dos produtores (PORTELA et al., 2002), e por isso, a sustentabilidade da agricultura familiar parece ser cada vez mais limitada. Essas limitações decorrem da modernização das atividades agrícolas e tem como consequência a exclusão dos produtores familiares que não conseguem acompanhar esse padrão tecnológico. Suas chances de reprodução social estão presentes geralmente no âmbito local, de forma específica, limitada e no curto prazo; outras dependem somente dos produtores, e se fazem por meio da pluriatividade e dos empregos não agrícolas (TELLES et al., 2008).

Além disso, $80 \%$ das propriedades possuíam baixo nível tecnológico, 20\% médio nível e nenhuma das propriedades estudadas se enquadrou no sistema de alto nível tecnológico 
de produção. Lopes et al. (2005) classificaram três níveis tecnológicos de produção: baixo nível tecnológico (propriedades que se enquadram em sistemas de produção que não possuem máquinas, implementos agrícolas e ordenhadeiras, com pequenos investimentos em instalações); médio nível (sistemas de produção intermediários); e altos níveis (sistemas de produção que possuem ordenhadeiras mecânicas do tipo leite canalizado, altos investimentos em máquinas e implementos agrícolas e instalações sofisticadas). Conforme Wagner et al. (2004), a diversificação das fontes de renda, por meio do desenvolvimento das diferentes culturas e criações, confere a permanência na atividade leiteira e reafirma a agricultura de base familiar como modelo sustentável de produção, independentemente da tecnologia adotada pelos mesmos.

Em 100\% das unidades produtivas estudadas, a forma de produção leiteira adotada era a convencional, ou seja, nenhuma destas utilizavam a produção agroecológica.

Para o plantio de pastagens e preparo de alimentos para os animais, 93,33\% das propriedades compravam as mudas de forrageiras utilizadas na alimentação dos animais, e apenas $6,67 \%$ produziam nas propriedades. Nenhum produtor realizava o melhoramento genético de espécies vegetais, $60 \%$ faziam uso de agrotóxicos e $40 \%$ não utilizavam nenhum tipo desses produtos.

A viabilidade econômica da agricultura de base familiar está em produzir alimentos com baixo custo e de qualidade para a população. Não se deve abrir mão de tecnologias de fácil aplicação a baixo custo e adaptadas à realidade local (SILVEIRA e MACHADO, 2009). As técnicas citadas anteriormente são alternativa para se obter pecuária mais viável economicamente e menos prejudicial à natureza. A maior parte das propriedades estudadas não utilizava ou utilizava muito pouco as práticas agroecológicas. Fato que pode estar relacionado à falta de informação sobre a importância econômica e ambiental dessas práticas. Conforme Abreu; Costa Neto (2007) é importante que não se tenha somente uma produção animal orgânica com traços capitalistas visando apenas à produção, mas à agricultura agroecológica, associando ainda o social e o meio ambiente.

\section{CONCLUSÕES}

Com o diagnóstico realizado nas unidades agrícolas familiares produtoras de leite, pode-se concluir que o perfil dos produtores é de agricultores familiares de baixa a media renda e que depende da produção do leite para a subsistência da família. As unidades leiteiras possuem deficiências de manejo do rebanho; os animais que constituem os rebanhos são mestiços e menos aptos para esse tipo de atividade produtiva. As práticas agroecológicas, são pouco utilizadas nas unidades estudadas.

Para que haja melhorias na produção de leite na região estudada é necessário que os laticínios paguem ao produtor pela qualidade do leite produzido e que os capacitem em práticas adequadas, transferindo aos produtores instruções adequadas inerentes a todo o ambiente de produção, fortalecendo este setor produtivo.

\section{AGRADECIMENTOS}

Este trabalho foi parte da dissertação da primeira autora para obtenção do título de Mestre em Ciências Agrárias pela Universidade Federal de Minas Gerais, campus Montes Claros. Os autores agradecem à FAPEMIG - Processo CVZ - APQ-03389-09, FAPEMIG - Processo CVZ - APQ-02761-11, MEC/ProExt/SESu - Edital n ${ }^{\circ} 05$ de 2010, PIBIC/CNPq, PROBIC/FAPEMIG e PBEXT/ UFMG. 


\section{REFERÊNCIAS}

ABREU, M. B.; COSTA NETO, C. Sustentabilidade agroecológica entre agricultores familiares assentados: um estudo da produção animal no assentamento Fazenda São Fidélis. In: CONGRESSO BRASILEIRO DE SISTEMAS DE PRODUÇÃO, 7., 2007, Rio de Janeiro. Anais... Rio de Janeiro: [s.n.], 2007.

ALENDE, C. R. M. Estudos do sistema de produção dos agricultores familiares da fronteira oeste do Rio Grande do Sul. 2006. 154 p. Dissertação (Mestrado Em Extensão Rural) - Universidade Federal de Santa Maria, Santa Maria, 2006.

ALTAFIN, I. G. et al. O mercado do leite em assentamentos de reforma agrária: acompanhamento e avaliação de ações técnicas e sociais. In: OLIVEIRA, M. N. de; XAVIER, J. H. V.; ALMEIDA, S. C. R. de; SCOPEL, E. (Ed.). Projeto Unaí: pesquisa e desenvolvimento em assentamentos de reforma agrária. Brasília: Embrapa Informação Tecnológica, 2009. p. 143-181.

ARAÚJO, L. V.; SILVA, S. P. Agricultura familiar, dinâmica produtiva e estruturas de mercado na cadeia produtiva do leite: elementos para o desenvolvimento territorial no Noroeste de Minas. Revista Brasileira de Gestão e Desenvolvimento Regional, v. 10, n. 1, p. 52-79, 2014.

BARRETO, L. C. N. Aspectos zootécnicos e sanitários de propriedades leiteiras do município de Itaperuna - RJ em 2005. 2007. 75 p. Tese (Doutorado em Ciência Animal) - Universidade Federal de Minas Gerais, Escola de Veterinária, Belo Horizonte, 2007.

BARROS, G. S. C.; GALAN, V. B.; GUIMARAES, V. A.; BACCHI, M. R. P. Sistema agroindustrial do leite no Brasil. Brasília:
Informação Tecnológica da EMBRAPA, 2001. 170 p. Disponível em: <http://livraria.sct. embrapa.br/liv_resumos/pdf/00075030.pdf $>$. Acesso em: 15 jan. 2012

BRASIL. Ministério da Agricultura, Pecuária e Abastecimento. Manual de Legislação: programas nacionais de saúde animal do Brasil. Ministério da Agricultura, Pecuária e Abastecimento. Secretaria de Defesa Agropecuária. Departamento de Saúde Animal. Brasília: MAPA/SDA/DSA, 2009. 440 p. Disponível em $:<$ http://www.agricultura. gov.br/arq_editor/file/Aniamal/Manual $\% 20$ de $\% 20$ Legisla $\%$ C3\%A7\%C3\%A3o\%20-\%20 Sa\%C3\%BAde\%20Animal\%20-\%201ow. pdf>. Acesso em: 15 fev. de 2012.

BRASIL. Lei n. 11.326, de 24 de julho de 2006. Estabelece as diretrizes para a formulação da política nacional da Agricultura Familiar e Empreendimentos Familiares Rurais. Diário Oficial da República Federativa do Brasil, Brasília, 25 jul. 2006. Disponível em: < http://www.planalto.gov. br/ccivil 03/ ato2004-2006/2006/lei/111326. htm>. Acesso em: 18 jun. 2012.

BUAINAIM, A. M.; ROMEIRO, A.; GUANZIROLI, C. Agricultura familiar e o novo mundo rural. Revista Dossiê Sociologias, v. 10, n. 5, p. 312-347, 2003.

CARVALHO JUNIOR, J. N. de. Diagnóstico da pecuária leiteira na microrregião de Itapetinga-Bahia. 2011.119 f. Doutorado (Tese em Produção de ruminantes) - Campus Itapetinga, Universidade Estadual do Sudoeste da Bahia, 2011.

CERDÓTES, L. et al. Produção e Composição do Leite de Vacas de Quatro Grupos Genéticos Submetidas a Dois Manejos Alimentares no Período de Lactação. Revista Brasileira de Zootecnia, v. 33, n. 3, p. 610-622, 2004. 
CERQUEIRA, M. M. O. P.; LEITE, M. O. Doenças transmissíveis pelo leite e derivados. Caderno Escolar técnico de Veterinária, v. 13, n. 16, p. 39-62, 1995.

DEL FAVA, C. et al. Manejo sanitário para o controle de doenças da reprodução em um sistema leiteiro de produção semi-intensivo. Arquivo do Instituto Biológico, v. 70, n. 1, p. 25-33, 2003.

DELGADO, F. E. F. et al. Verminoses dos bovinos: percepção de pecuaristas em Minas Gerais, Brasil. Revista Brasileira de Parasitologia Veterinária, v. 18, n. 3, p. 29-33, 2009.

INSTITUTO BRASILEIRO DE GEOGRAFIA E ESTATÍSTICA (IBGE). Nota Técnica: Estimativas da população residente com data de referência $1^{\circ}$ de julho de 2011. Disponível em: <http://www.ibge.gov.br/ home/estatistica/populacao/estimativa2011/ default.shtm>. Acesso em: 15 set. 2012.

\section{IBGE/SIDRA. Produção da Pecuária} Municipal 2010. Rio de Janeiro: IBGE, 2011. Disponível em: <http://www.ibge.gov.br/ home/estatistica/populacao/estimativa2011/ default.shtm>. Acesso em: 15 set. 2012.

KRUG, E. E. B. Estudo para identificação de benchmarking em sistemas de produção de leite no Rio Grande do Sul. 2001.194 f.(Mestrado em Administração para Executivos) - Faculdade de Administração, Universidade Federal do Rio Grande do Sul, Porto Alegre, 2001. Disponível em: <http:// hdl.handle.net/10183/2191>. Acesso em: 10 jan. 2012.

LEITE, T. E.; MORAES, J. C. F.; PIMENTEL, C. A. Eficiência produtiva e reprodutiva em vacas leiteiras. Ciência Rural, v. 31, n. 3, p. 467-472, 2001.
LOPES, M. A. et al. Efeito do tipo de sistema de criação nos resultados econômicos de sistemas de produção de leite na região de Lavras (MG). Ciência e Agrotecnologia, v. 28, n. 5, p. 1177-1189, 2004.

LOPES, M. A. et al. Resultados econômicos de sistemas de produção de leite com diferentes níveis tecnológicos na região de Lavras, MG. Arquivo Brasileiro Medicina Veterinária e Zootecnia, v. 57, n. 4, p. 485 493, 2005.

MARCON G. C. et al. Productive and technological aspects of dairy cattle from Sinop, Mato grosso, Brazil. Scientific Electronic Archives, v. 5, n. 1, p. 72-82, 2014.

MENDES, M. et al. Determinação da prevalência das principais doenças da reprodução no rebanho bovino da região de Uberaba-MG. Ciência Animal Brasileira, supl. 1, p. 772777, 2009.

MONTEIRO, A. A. et al. Características da produção leiteira da região do agreste do estado de Pernambuco, Brasil. Semina: Ciências Agrárias, v. 28, n. 4, p. 665-674, 2007.

PORTELA, J. N. et al. Indicadores de desempenho zootécnico observados nas unidades de produção familiar associadas à cooperativa dos produtores de leite de Santa Maria (COOPROL), RS. Ciência Rural, v. 32, n. 32, 485-491, 2002.

SCHNEIDER, S. Teoria social, agricultura familiar e pluriatividade. Revista Brasileira de Ciências Sociais, v. 18, n. 51, p. 99-122, 2003.

SEBRAE/FAEMG. Diagnóstico da pecuária leiteira do estado de Minas Gerais em 2005: relatório de pesquisa. Belo Horizonte: 
FAEMG, 2006. 156 p. Disponível em: <http:// www.faemg.org.br/Cbontent.aspx?Code $=6$ 065\&fileDownload=True $>$ Acesso em: 26 jun. 2012.

SILVA, J. A. et al. Uso da terra como determinante da distribuição da raiva bovina em Minas Gerais, Brasil. Arquivo Brasileiro de Medicina Veterinária e Zootecnia, v. 53, n. 3, p. 273-383, 2001.

SILVA, L. L da. Organização social, estratégias produtivas e programas de desenvolvimento: Estudo de caso da comunidade Roda D’água, município de Januária, MG. 2010.127 f. Dissertação (Mestrado em Agroecologia) - Instituto de Ciências Agrárias, Universidade Federal de Minas Gerais, Montes Claros, 2010.

SILVEIRA, A. L. R.; MACHADO, L. Pastoreio Direto em Cana (Saccharum officunarum L.). Revista Brasileira de Agroecologia, v. 4, n. 2, p. 4172-4175, 2009.

SOUZA, R. P. de; WAQUIL, P. D. A viabilidade da agricultura familiar produtora de leite: o caso do sistema CORLAC (RS) - UFRGS. 2008. 136f. Dissertação (Mestrado em Desenvolvimento Rural)
- Faculdade de Ciências Econômicas, Universidade Federal do Rio Grande do Sul, Porto Alegre, 2008. Disponível em: <http:// hdl.handle.net/10183/11921>. Acesso em: 18 mar. 2012.

TELLES, T. S.; TANAKA, J. M. U.; PELLINI, T. Agricultura familiar: pecuária leiteira como locus das políticas públicas paranaenses. Semina: Ciências Agrárias, v. 29, n. 3, p. 579-590, 2008.

TKAEZ, M. et al. Níveis microbiológicos e físico-químicos do leite in natura de produtores do Estado de Santa Catarina. In: CONGRESSO BRASILEIRO DE QUALIDADE DO LEITE, 1., 2004, Passo Fundo. Anais... Passo Fundo: [s.n.], 2004. 1 CDROM.

VIEIRA, G. A. Produção intensiva de bovinos de corte: análises e perspectivas. Revista Nacional da Carne, v. 29, n. 342, p. 131-134, 2005.

WAGNER, S. A.; GEHLEN, I.; WIEST, J. M. Padrão tecnológico em unidades de produção familiar de leite no Rio Grande do Sul relacionado com diferentes tipologias. Ciência Rural, v. 34, n. 5, p. 1579-1584, 2004. 


\section{C) MILAIN OX ${ }^{\circledR}$}

\section{A dose certa de tecnologia para sua indústria.}

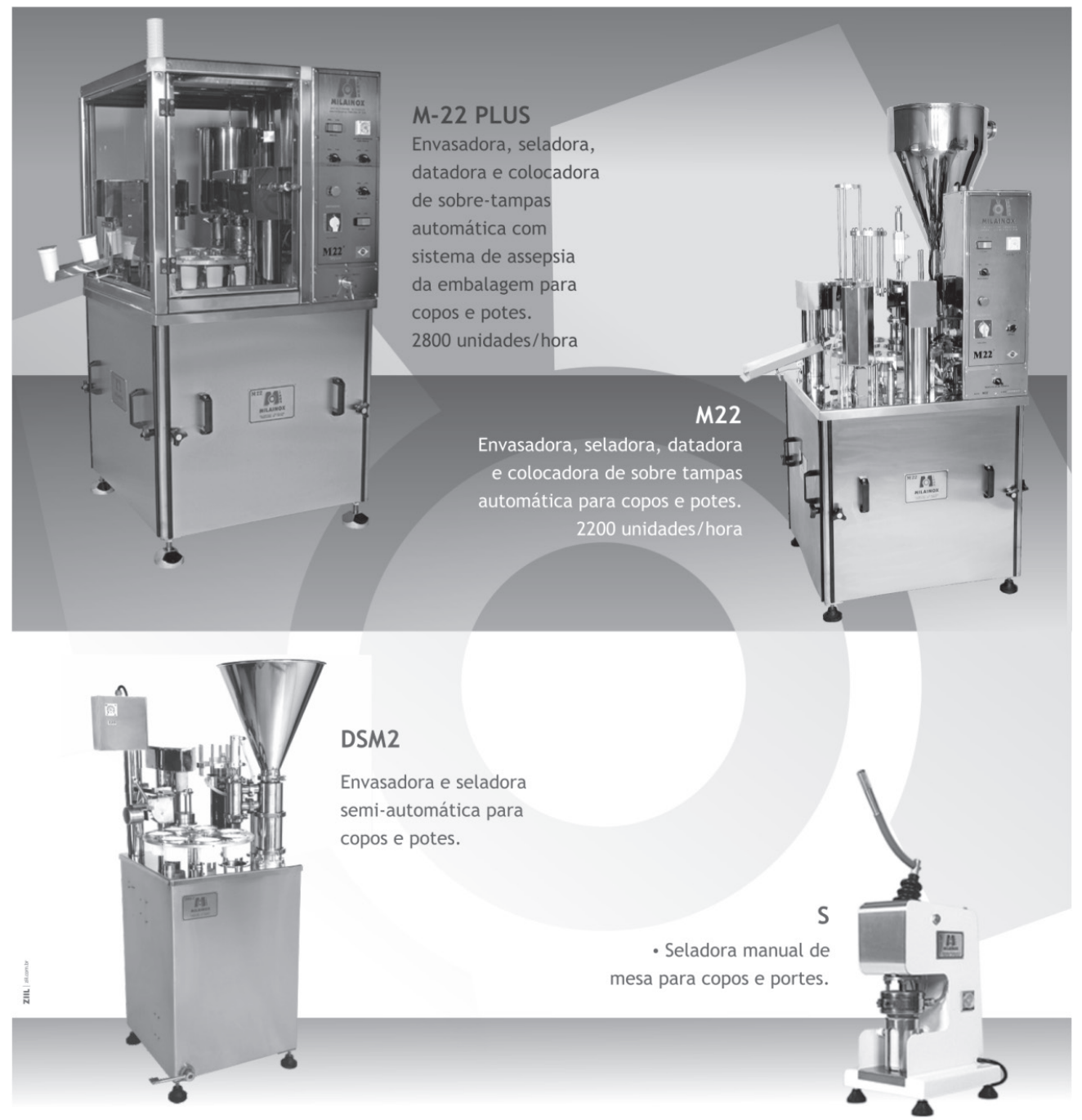

Piracicaba - SP - Brasil | (19) 3447-8950 / (19) 3422-3051 / (19) 3433-3051 / (19) 9756-7361 www.milainox.com.br /atendimento@milainox.com.br 